\title{
Health of teenagers in residential care: comparison of data held by care staff with data in community child health records
}

\author{
A Bundle
}

\begin{abstract}
Aim-To identify whether there are gaps in information available to care staff about the health related needs of one group of teenagers in residential care which could be addressed by reviewing the community child health records.

Methods-Data were collected on the residents of a children's home during a three month period, comparing information from children's home records with information from community child health records.

Results-Data were collected from children's home records for 36 residents and child health records obtained for 29 . Child health records provided the only information on $53 \%$ of child protection registrations and $17.5 \%$ of statements of special educational needs. Most information on birth history, developmental and early medical history, immunisations, growth, hearing, and colour vision came from the child health records. Immunisation uptake was below the national average, and particularly poor for BCG and school leaver tetanus, low dose diphtheria, and polio boosters. Emotional and behavioural problems were present in $100 \%$ of the residents and this information was known to the home. Poor use of "Looking After Children" records was identified, and there was a paucity of information in the home records and child health records about results of annual looked after medical examinations.
\end{abstract}

Conclusion-Important information about the health needs of looked after teenagers was not known to the children's home staff. Community paediatricians should be proactive in identifying and addressing these needs.

(Arch Dis Child 2001;84:10-14)

Health 1, Winnington Hall, Winnington,

Northwich, Cheshire CW8 4DU, UK

A Bundle

Correspondence to: Dr Bundle

annabelle.bundle@which.net

Accepted 3 August 2000
" United Kingdom the term "lor ren accommodated voluntarily as well those subject to legally enforceable orders.
Looked after children are entitled to the same opportunities for love, care, health, education, and safety as all other children. This is often not their experience, however, largely because of the reasons which determined they are unable to live with their families, but, at times, also because of their experiences within the "care" system. Abuse is a contributory factor to placement for many looked after children. ${ }^{12}$ However, breakdown of family relationships is a significant cause of many teenagers being in residential care. ${ }^{3}$

The implementation in the UK of the Children Act 1989 changed the emphasis in children's welfare from removal of the child from the family to retention within the family wherever possible. ${ }^{4}$ Consequently, those children who currently spend time in residential care tend to be those who are older and have experienced previous placement breakdown, with those in secure accommodation being among the most damaged adolescents. ${ }^{56}$

Lack of information about past medical and family history is common and accurate information about current health status, especially immunisations, is frequently absent. ${ }^{7-10}$ This is particularly likely for those who have experienced multiple placements. ${ }^{11}$ Much information may be contained in the community child health records but there is limited evidence in the literature to indicate the utilisation of this resource.

This research, therefore, seeks to identify what additional information about the health of young people in residential care would be available if the community child health records were reviewed.

\section{Methods}

STUDY SETTING

The study was conducted in a mixed residential children's home for young people aged 12-16+ years, which has a school on site. The home has 32 beds, of which eight are in a secure setting. The home is a national facility and is suitable for young people who have experienced previous placement breakdown and school failure. All young people are offered appointments with an optician, dentist, and the general practitioner for the home. 
Table 1 Reasons for placement

\begin{tabular}{ll}
\hline Reason for placement & Number of young people \\
\hline Risk of significant harm & 23 \\
Absconding & 13 \\
Challenging behaviour & 10 \\
Placement breakdown & 10 \\
Beyond parental control & 8 \\
Criminal offences & 8 \\
Abuse & 4 \\
Family breakdown & 1
\end{tabular}

Some young people had more than one reason for current placement.

METHODS

Children's home records-Between August and November 1998, the children's home records were reviewed to identify information about the health related needs of all young people resident at the home for longer than 72 hours.

Community child health records-Community child health records were requested for all residents whose home records were reviewed, to identify information about health related needs that was not already available in the children's home records.

Exclusions from the study-Young people on emergency placements were excluded from the study because there was insufficient time to review their records before discharge.

SAMPLE

Forty six young people were resident at the home during the data collection period. Ten were admitted on an emergency basis and therefore excluded from the study. The number for whom data were collected was 36 (19 males). Community child health records were obtained for 29. The age range was 13-16 years, with more males at the younger and more females at the older end of the age range. All were white. The mean number of placements per child was six (range 1-32; mode = 3). The mean length of time being looked after was 30.9 months (range 2 months to 13 years). Eight residents had experienced multiple episodes in care.

Twenty two residents were accommodated and eight were subject to care orders. Six were subject to secure accommodation orders, and two were remanded under section 23 of the Children and Young Persons Act 1969. Two residents were subject to supervision orders and one was bailed under section 53 of the Children and Young Persons Act 1933. These categories are not mutually exclusive. Table 1 shows reasons for placement.

\section{Results}

CHILD PROTECTION REGISTRATIONS

Details of child protection registrations were available for 17 young people. It was unclear how many were current registrations. Details of nine $(53 \%)$ were found only in the child health records.

EDUCATION

Thirty three young people were educated at the on site school and three attended other schools. Seventeen had a statement of special educational needs. Details of 11 statements were known in full from the children's home records and in part for a further three. For these three, and the remaining three, full details were available in the child health records. Sixty per cent of statements were for emotional and behavioural disorders.

BIRTH, DEVELOPMENTAL, AND EARLY MEDICAL HISTORY

Specific information about birth, developmental, and early medical history was completely lacking in the children's home records for 35 young people, with partial information available for one. Full details were available from the child health records for 27 young people.

PAST MEDICAL HISTORY

Limited information about past medical history was available in the children's home records for 26 young people. Information known only from the child health records included one with a congenital abnormality of one ear, one with absence of the left kidney and reimplantation of the right ureter, five with a history of speech and language problems, and five with a history of coordination difficulties. The child health records were the main source of information about previous accidents and injuries.

GROWTH, HEARING, VISION, AND COLOUR VISION Some information about growth was available for two young people from the children's home records and for an additional 24 from the child health records. Growth centiles were recorded for only 18. Details of audiometry were available for 10, all from the child health records. Three young people were recorded as having hearing problems (one in the children's home record), but no action was recorded as having been taken. Details of vision were recorded in the children's home records for 15 and for a further 15 in the child health records. Colour vision results were known only from the child health records, and were available for 15

\section{IMMUNISATIONS}

The children's home records contained partial information about immunisations for five young people, of which three had dates. Full details of immunisations, with dates, were available in the child health records for 12 , and partial information, with dates, for a further 17. Recorded immunisation uptake from 29 sets of child health records was as follows: completed primary course $86 \%$; preschool booster $69 \%$; MMR or measles $76 \%$; MR $65.5 \%$; BCG $38 \%$; school leaver tetanus, low dose diphtheria, and polio $0 \%$.

CURRENT MEDICAL PROBLEMS

Some details of current medical problems were recorded in the children's home records for 17 young people. Eighteen had a medical consultation with the general practitioner, details of which were included in the children's home records. New diagnoses were made for nine young people. Including these, there were current medical problems for 20, some of whom had more than one diagnosis. The child health records provided supplementary 
Table 2 Current medical problems

\begin{tabular}{ll}
\hline Condition & Number of young people \\
\hline Dental & 10 \\
Possible sexually transmitted disease & 4 \\
Reduced visual acuity (spectacles & 4 \\
$\quad$ prescribed) & 4 \\
Asthma & 3 \\
Hearing loss & 3 \\
Hay fever & 3 \\
Nocturnal enuresis & 3 \\
Infection requiring antibiotics & 2 \\
Eczema & 2 \\
Insomnia & 2 \\
Abdominal pain & 1 \\
Heart murmur & 1 \\
Fracture & 1 \\
Congenital abnormality of ear & 1 \\
Lump on knee & 1 \\
Premenstrual tension & 1 \\
Secondary amenorrhoea & 1 \\
Gynaecomastia & 1 \\
Grade 3 Heaf test & 1 \\
Coccydynia & 1 \\
Menorrhagia &
\end{tabular}

Table of current medical problems identified from children's home record, general practitioner consultation, and child health record.

Table 3 Emotional and behavioural disorders

\begin{tabular}{lc}
\hline Emotional/behavioural disorder & Number of young people \\
\hline Criminal (other) & 27 \\
Behaviour problems (unspecified) & 25 \\
Absconding & 8 \\
Self harm & 8 \\
Conduct disorder & 5 \\
Sexual crime & 3 \\
Sexual abuser & 3 \\
Suicidal ideation & 3 \\
Hyperactive & 2 \\
Attempted murder & 1 \\
Depression & 1 \\
Post traumatic stress disorder & 1 \\
Attachment disorder & 1 \\
Making false allegations of abuse & 1
\end{tabular}

Many young people had more than one emotional/behavioural problem.

information about one current medical problem. Table 2 shows details of current medical problems.

EMOTIONAL AND BEHAVIOURAL PROBLEMS

Professional concern about emotional and behavioural problems was present in the children's home records for $100 \%$ for the young people in the study. Additional information about previous concerns was found in the child health records for 16 . Table 3 gives details of emotional and behavioural problems.

SUBSTANCE USE

Sixteen young people were recorded as having misused illicit drugs. Information about three was known only from the child health records. Illicit drug use occurred across the age range and the commonest substance used was cannabis. Heroin was used by three and multiple drug use occurred in four. Illicit drug use occurred in $42 \%$ of males and $47 \%$ of females. Concerns about alcohol misuse were present for 10 females and eight males. Information about two was known only from the child health records. All ages were represented. Information about smoking was obtained solely from the home records and is likely to be an underestimate of the number actually smoking. A smoking consent signed by a person with parental responsibility was filed in the children's home records for 10 males and seven females. All ages were represented.

\section{SEXUAL HEALTH}

Professional concern about sexual health was recorded in the children's home records for seven males and 13 females, with information about one additional male recorded in his child health record. Of these 21 young people, six had committed sexual offences, four had possible sexually transmitted infections, four exhibited sexualised behaviour, four were thought to have been involved in prostitution, three were sexually promiscuous, and one required a pregnancy test.

ANNUAL LOOKED AFTER MEDICAL EXAMINATION Eleven young people were recorded as having an annual looked after medical examination at some time, but little information about outcome was available in either the children's home or child health records.

LOOKING AFTER CHILDREN RECORDS

"Looking After Children" records ${ }^{12}$ were present in the children's home records for 24 residents, but the information contained in them was frequently sparse, particularly in relation to health.

\section{Discussion}

This study was undertaken to identify gaps in information about the health needs of young people in residential care. The study home did not have a designated community paediatrician nor did the on site school have a school nurse. Therefore, the community child health records were not routinely reviewed when a young person was admitted to the home.

The study home cares for teenagers who have experienced disrupted placements, school failure, and are considered difficult to place. The prevalence of emotional and behavioural problems in this group is greater than in other studies and is likely to reflect their past experiences. ${ }^{13-16}$ Most information about current emotional and behavioural concerns, and substance misuse, was known to the staff of the children's home through the home records. However, some information about previous concerns was found in the child health records and may be important in understanding the underlying causes and directing therapeutic input appropriately.

Almost half the teenagers in this study had been on a child protection register at some time. Of particular concern is the finding that details of registration for 53\% were identified only from the child health records. Therapeutic help for such children is frequently inadequate and problems will be compounded by ignorance by care staff of previous child protection concerns. ${ }^{17} 18$

Poor school attendance has been noted in other studies and needs to be addressed by staff in children's homes promoting educational opportunities. ${ }^{17} 1920$ The incomplete or absent information about statements of special educational needs available to the staff 
of the on site school for six young people is of great concern, as such information is essential if the child's educational needs are to be met. The child health records contained full details of all the statements, but should not be regarded as the main source of this information. However, the medical examination and collating of medical information undertaken by community paediatricians as part of the formal assessment of special educational needs may provide valuable information about health at that time.

Looked after children over the age of 2 years should have a medical examination carried out annually. ${ }^{21}$ This study highlights the lack of information in both the children's home records and the child health records about the outcome of the few annual medical examinations recorded as having been undertaken. This raises the question of where this information is held and whether action is taken when required. This could form the subject of an interagency audit. The uptake of this examination is poor and may not be the most appropriate way to assess the health of teenagers. ${ }^{911} 22$ Concern about confidentiality is a significant reason for young people refusing consent to the medical examination. ${ }^{9}{ }^{23}$ Young people under the age of 16 have the right to make their own informed choices about consent to treatment, provided they are of sufficient maturity to understand the implications of their decision. Equally, they have the right to confidentiality if they have the maturity to understand what it means to trust someone with information..$^{25}$ Sharing of information without parental consent is permissible where it is in the child's best interests, but the information shared should only be that which is required by the other person to carry out their professional responsibilities. It would be reasonable to discuss with teenagers the information to be shared and to seek their consent to its disclosure. This would also provide an opportunity to discuss the implications of past health, development and family history, and current health concerns.

The children's home records contained information about most of the current medical problems, including those identified at general practitioner medical consultations. New medical problems were identified for $50 \%$ of those who consulted a general practitioner. Therefore, some form of examination, where clinically indicated, will be required for some young people. However, the child health records were the main source of information about some important aspects of developmental history, as well as birth and early medical history and immunisations.

In this study, the particularly poor uptake of BCG and school leaver tetanus, low dose diphtheria, and polio boosters may reflect absence from school and the difficulty of keeping track of immunisations and other health needs when there are frequent placement changes. Incomplete immunisations in looked after children have been noted previously. ${ }^{79}$ This is one area where community paediatricians should take a proactive approach to obtaining consent and arranging immunisation sessions.
Knowledge about growth, hearing, and colour vision was almost entirely dependent on access to the child health records. However, even in these records, this information was unavailable for some children. A school nurse undertaking screening procedures at entry to the home would overcome some of these deficiencies and this could also provide health promotion opportunities.

In this study, only 29 sets of child health records were obtained, although 36 were requested. This highlights the difficulties of ensuring continuity of information about the health of looked after children. Although Looking After Children records should contain basic health information, their use in this study was limited. This needs to be addressed, as these records, used consistently, could overcome some of the problems identified. A record retained by the young person should also be considered. ${ }^{10} 11$ The appointment of a designated doctor for looked after children would facilitate liaison between health professionals when children experience placement moves. ${ }^{11}$

These are issues which have been raised in the Department of Health consultation document Promoting health for looked after children, which also suggests that the general practitioner record should be the main health record for looked after children. ${ }^{23}$ If this is to be the case, liaison with other health professionals will be vital to ensure important information is not overlooked. Particularly for children who have lived away from their birth family for a long time, or who have experienced a number of placement moves, the community child health record is an important source of information that may not be available elsewhere. Part of any health assessment for looked after children should, therefore, be the review of all existing sources of information about a child's health.

This research was undertaken for the MMedSc in Child Health, University of Leeds, UK. The author is grateful to Dr S Wyatt and Dr M Rudolf for their advice. Thanks are due also to Brian Ford, Community Liaison Officer, and the staff at the Social Services Research Library, Chester.

1 Laming H. Social services facing the future. The seventh annual report of the Chief Inspector Social Services Inspectorate 1997/8. London: The Stationery Office, 1998.

2 Health Committee Report. Children looked after by local authorities. Second Report, Vol. 1. London: The Stationery Office, 1998.

3 Sinclair I, Gibbs I. Quality of care in children's homes. Department of Health Research Project 370/0317, Social Work Research and Development Unit, Working Paper Series B, No 3. York: University of York, 1996.

4 Children Act 1989. London: HMSO.

5 Takayama J, Wolfe E, Coulter K. Relationship between reason for placement and medical findings among children son for placement and medical findings among

placed in foster care. Pediatrics 1998;101:201-7.
6 Bullock R, Little M, Millham S. Secure treatment outcomes: the care careers of very difficult adolescents. In: Department of Health report, Caring for children away from home. Messages from research. Chichester: John Wiley \& Sons Ltd, 1998.

7 Chernoff R, Combs-Orme T, Risley-Curtis C, Heisler A. Assessing the health status of children entering foster care. Pediatrics 1994;93:594-601.

8 Halfon N, Mendonca A, Berkowitz P. Health status of children in foster care. Arch Pediatr Adolesc Med 1995;149:38692.

9 Mather M, Humphrey J, Robson J. The statutory medical and health needs of looked after children. Time for a radical review. Adoption and Fostering 1997;21:36-9.

10 Irving M, Evans S, Watson L. British Agencies for Adoption Irving M, Evans S, Watson L. British Agencies for Adoption
and Fostering in Scotland-Scottish medical advisers and Fostering in Scotland-Scottis

11 Butler I, Payne H. The health of children looked after by the local authority. Adoption and Fostering 1997;21:28-35. 
12 Department of Health. Looking after children assessment and action records. London: HMSO, 1995.

13 Department of Health. Caring for children away from home. Messages from research. Chichester: John Wiley \& Sons Ltd, 1998.

14 McCann J, James A, Wilson S, Dunn G. Prevalence of psychiatric disorders in young people in the care system. $B M f$ 1996;313:1529-30

15 Schneiderman $M$, Connors $M$, Fribourg A, Griew L, Gonzales M. Mental health services for children in out-ofhome care. Child Welfare 1998;LXXVII

16 Stein E, Rae-Grant N, Ackland S, Avison W. Psychiatric disorders of children "in care": methodology and demographic correlates. Can 7 Psychiatry 1994;39:341-7.

17 Berridge D, Brodie I. Children's homes revisited 1998. In: Department of Health report, Caring for children away from home. Messages from research. Chichester: John Wiley \& Sons Ltd, 1998.

18 Farmer E, Pollock S. Sexually abused and abusing children in substitute care. In: Department of Health report, Caring for children away from home. Messages from research. Chichester: John Wiley \& Sons Ltd, 1998

19 Sinclair I, Gibbs I. Children's homes: a study in diversity. In: Department of Health report, Caring for children away from home. Messages from research. Chichester: John Wiley \& Sons Ltd, 1998.

20 Youdan P. Children need champions. Community Care 1998;7:26 March to 1 April.

21 Department of Health. Children and young persons - review of children's cases regulations. London: HMSO, 1991.

22 Polnay L, Glaser A, Rao V. Better health for children in resident care. Arch Dis Child 1996;75:263-5.

23 Department of Health. Promoting health for looked after children. Consultation document. London: Department of Health, 1999.

24 Department of Health, Home Office, Department for Education and Employment. Working together to safeguard children. London: The Stationery Office, 1999.

25 Hendrick J. Legal aspects of child health care. London: Chapman \& Hall, 1997.

\section{Cochlear implantation}

For most children with impaired hearing, an acoustic hearing aid is the means through which they hear speech. For the few who cannot achieve speech perception in this way cochlear implantation may be necessary. Throughout the world some 10000 or more children have had a cochlear implant, but there is considerable variation in results as regards speech perception. Researchers in Nottingham (Gerard M O'Donoghue and colleagues. Lancet 2000;356:466-8) have attempted to define the origins of this variation.

Their study included 40 children who were unable to hear speech with an acoustic hearing aid. In all of them the hearing disability dated from birth or within three years' of birth (mean age at onset, 12 months). Twenty-three were deaf from meningitis and 13 were congenitally deaf. The age at implantation ranged from 30 months to 7 years (mean 52 months). Before implantation, 14 communicated orally and 26 used a total communication approach including signing.

The children were followed up for five years after implantation and assessed using connecting discourse tracking (CDT) in which text is read out to the child and the number of words per minute repeated correctly is recorded. Performance improved gradually over the five years, the mean CDT score being 27 words/min after three years, 35 after four years, and 45 after five years. Two factors were strongly related to better CDT performance; the children were younger at implantation and had oral communication before implantation. The cause of the deafness, the number of electrodes implanted, and social class did not affect speech perception achieved.

Speech perception is not the only worthwhile outcome. Lesser achievements such as relief from auditory isolation, facilitation of lip reading, and hearing of warning sounds may be worthwhile even in the absence of speech perception. Universal neonatal hearing screening is important so that congenitally deaf children can be detected early.

ARCHIVIST 